\title{
De cânticos, rosas e desesperanças: algumas reflexões sobre a poesia em Cabo Verde no período da pós-independência
}

Carmen Lucia Tindó Secco

Universidade Federal do Rio de Janeiro

RESUMO: A PARTIR DA ANÁLISE DE TEXTOS DA LITERATURA CONTEMPORÂNEA CABOVERDIANA, ELABORA-SE UMA REFLEXÃO SOBRE A PRODUÇÃO DE AUTORIA FEMININA RECENTE DO ARQUIPÉLAGO, DANDO-SE DESTAQUE AOS TEXTOS DE VERA DUARTE.

ABSTRACT: BASED ON THE ANALYSIS OF TEXTS FROM CONTEMPORARY CAPE VERDIAN LITERATURE, A REFLECTION ON THE RECENT FEMININE AUTHORSHIP FROM THE ARCHIPELAGO IS ELABORATED, BY EMPHASIZING VERA DUARTE'S TEXTS.

PALAVRAS-CHAVE: LITERATURA CABOVERDIANA, AUTORIA FEMININA, VERA DUARTE. KEY-WORDS: CAPE VERDIAN LITERATURE, FEMININE AUTHORSHIP, VERA DUARTE. 
inda, em grande parte, a euforia gerada pela Independência de Cabo Verde, no final dos anos 80 e início dos 90, as novas gerações de escritores caboverdianos, em seus textos literários, começaram a denunciar o vazio cultural existente no mundo e no Arquipélago, além de constatarem que a fome e a miséria não haviam sido extintas da nação recém-libertada. Apareceu, então, um acentuado sentimento de desânimo em relação aos valores cantalutistas que animaram a poética libertária. A poesia deixou de cantar apenas o social e passou a operar também com os sentimentos individuais, com o existencial e o universal. Um novo lirismo se erigiu, cheio de construções metapoéticas, repensando tanto os caminhos sociais, como os da poesia.

Em 1991, houve a publicação de Mirabilis: de veias ao sol (ALMADA, J.L. H.,1991, p. 1-347), antologia organizada por José Luís Hopffer Almada, que reuniu os "novíssimos poetas de Cabo Verde", divulgando a produção poética cabo-verdiana pós-25 de Abril. O não cumprimento das promessas de justiça social, depois da Independência, gerou um clima de intensa decepção. Entretanto, lembrando-se de que, mesmo no deserto, geralmente cresce uma planta chamada mirabilis, nasceu a geração mirabílica, oferecendo-se como resistência poética a esses anos de "mau tempo literário". Na apresentação da antologia, seu organizador, José Luís Hopffer Almada, define a profissão de fé desses novíssimos poetas, cuja poesia empreende uma profunda reflexão sobre o presente cabo-verdiano:

Fustigada pelos ventos ( da incompreensão!), pelo sol ( da hipocrisia!), pelos tempos vários do mau tempo literário, desse tempo querendo-se vegetação literária. No deserto, cresce a geração mirabílica, feita signo na margem desértica do mar. De veias ao sol. As veias da indagação. As veias alagadas da terra das estradas, da poeira do dia-a-dia, do massapé dos campos, do lixo dos caminhos suburbanos, do desespero recoberto de moscas, baratas e outros vermes. As veias loucas do mar, do marítimo lirismo dos dias afogados nos ciúmes dos montes. As veias, veias de vida, de morte, de desespero, das quatro estações místicas do que se medita no refúgio do silêncio. Veias do camponês e da enxada neste coito de séculos com a terra. Ao sol, hipócrita por entre a bruma e os cerros. Sol, signo de luz. Sol que ilumina. Sol que queima e ofusca o caminhar. Sol dependurado da perseverança secular. Mirabilis _ de veias ao sol .Geração mirabílica indagando o sol. "No Deserto cresce a Mirabilis". Diz o poeta Orlando Rodrigues. 
"Embora de veias ao sol". Adita Rodrigo de Sousa, para que das imagens do deserto cresçam as palavras da nossa geração e delas reste, ao menos, o cadáver da poesia. Sugere Mito, o poeta plástico, ou que o cadáver se metamorfoseie em flor e espinho, num panorama azul, de onírico, sugere Mito, o plástico poeta. Uma única rosa é a Mirabilis, e dela queda um sol de sangue. $\mathrm{O}$ sol da poesia mirabílica. ( ALMADA, J. L. H., 1991, p.26-27)

Entre os poetas da geração mirabílica, constam os nomes de Dina Salústio, Vera Duarte e outras mulheres que fundaram uma poética feminina em Cabo Verde.

As metáforas marítimas sempre estiveram presentes nas composições poéticas de Cabo Verde, mas, nas primeiras gerações, o oceano aparecia como elemento enclausurador. As mulheres encontravam-se presas ao cais, esperando, submissas, os amantes, filhos e maridos que saíam para a pesca da baleia ou iam estudar em Portugal. O mar como magma da memória e do inconsciente feminino é uma conquista da novíssima poesia cabo-verdiana que persegue os labirintos interiores do desejo da mulher-poeta. Uma das representantes dessa poética atual é Vera Duarte, cujos versos assinalam o direito feminino à eroticidade do próprio corpo e da voz. Vera inaugura com sua poesia um universo poético assinalado pela "cumplicidade das fêmeas" (GOMES, S. C., 1993, p. 63), no qual a mulher almeja ser sujeito de seu próprio desejo:

...choro da dor de me saber mulher feita não para amar mas para ser amada. Choro porque sou e amo. (...) Sinto-me escravizada, tiranizada, violentada. E meu ser nascido livre se revolta. (..) Por isso quero desvendar os universos proibidos e purificar-me. (DUARTE, V., 1993, p. 40)

Com essa poética de contestação à submissão feminina, Vera Duarte rompe com a idéia do "cais da sôdade", onde, durante quase toda a história de Cabo Verde, as mulheres, circunscritas ao espaço das ilhas, choravam a saudade dos maridos, noivos, filhos. Assumindo-se também narrador, o sujeito-poético mergulha em uma poesia confessional, autobiográfica que instaura uma "escrita de mulher". Uma escrita que se rebela contra a longa espera das "mulheres-sós de Cabo Verde" (SANTILLI, M. A, 1985, p.107), a que se referiu a Profa. Maria Aparecida Santilli, fazendo uma crítica ao machismo cabo-verdiano. 
Nos poemas de Vera Duarte, a mulher não se encontra na terra, mas flutuando no imenso mar, símbolo de sua memória e do inconsciente coletivo de seu povo:

... eu penetrava no mar, um mar verde e lodento que se me escorregava debaixo dos pés e me causava náuseas. com a água pela cintura e os braços em arco , passava por entre os barcos de minhas viagens de antanho, marinheiro descobridor do mundo ... (DUARTE, V., 1993, p. 54)

Realiza, desse modo, uma travessia imaginária em relação às próprias origens. O mar é o local da busca da identidade cabo-verdiana, mas é também o lugar da liberdade existencial, espelho onde a poesia feminina se descobre. Uma poesia dialógica, à procura do amante e do leitor, em que os versos, em cópula constante, fazem a libido se derramar e brotar do próprio ato de produção da leitura que se abre a reflexões metalingüísticas: Para que servem as palavras? Para flutuar, perdida à mercê delas? (DUARTE, V., 1993, p. 38)

No livro O Arquipélago da Paixão, o sujeito lírico dos poemas de Vera Duarte ultrapassa a condição de mulher submissa, subjugada pelas desditas amorosas. Supera os sentimentos de autocompaixão e desabrocha a sensualidade reprimida. Não mais se sentindo inferior ao amado, a amada se torna também amante, senhora de si e declara:

\author{
Mas hoje \\ Dona dos meus jardins \\ Livre e insubmissa \\ Ajoelho-me a teus pés \\ Em sinal d'amor e liberdade.( DUARTE, 2001, p. 58)
}

A mulher-poeta ingressa na esfera de Eros, buscando a plenitude de um amor gerador de possibilidades de poesia no encontro com o outro. Não mais a poesia produzida pelas frustrações da paixão, mas a poesia da paixão. A transformação dos desejos que não podem se concretizar na paixão amorosa no desejo de outra coisa que a poesia (no sentido lato, não apenas no sentido da produção de poemas) pode realizar (KEHL, M.R., 1987, p.484). O eu-lírico toma ciência, então, de que suas mágoas e decepções não são maiores do que as de seu povo. Olha para o que está 
à sua volta e percebe a crise dos paradigmas sociais. Com a clareza de que a Madrugada anunciada com a Independência não foi plena, pois, após a euforia, o que restou "foi o gosto amargo das desilusões" (DUARTE, V., 2001, p. 61), traz a reflexão política para os domínios da arte e da poesia. Passa, então, ao inventário de outras paixões: a dos sofrimentos sociais existentes não só em Cabo Verde, mas em outras partes do mundo. Consciente do vazio atual de utopias, da carência das antigas esperanças que inflamaram os movimentos revolucionários em prol da Liberdade, o sujeito poético invoca a memória de heróis da resistência que lutaram contra diversas formas de opressão:

Quero poder ouvir

para sempre

as canções heróicas

1eu deram som às revoluções

(...)

quero poder

por meus pés

cruzar ares

cruzar mares

conhecer gentes

cantar Independências

e tudo que cheirar liberdade

(...)

Que me importa se

_ no fim_

ela (ainda) não foi possível

o que quero ter nos braços

é a idéia de a ter

e poder cantar abril

(...)

quando tudo o que restou

foi o gosto amargo das desilusões.

(DUARTE, V., 2001 , pp. 60-61) 
$\mathrm{Na}$ clave da paixão, a mulher assume o prazer. Torna-se dona não só de seu próprio corpo, mas do de seu amado, comandando os jogos amorosos num corpoamor com a própria linguagem poética. E é dessa febre desesperada que lhe vem um maior conhecimento de si e do mundo. Enlaçam-se, desse modo, os corpos amantes e é dissolvida a distância objetiva que a história positivista sempre estabeleceu entre razão e paixão. Estas, fundidas em um só corpo, comprovam que o sujeito passional também pode ser racional, uma vez que o ser humano só está inteiro nas suas paixões:

O amor sublime não abre mão da paixão, mas sabe transformar o impossível da paixão em possibilidade de troca simbólica. É quando o outro fala comigo, é quando dois universos simbólicos se tocam, se interpenetram, frutificam, se potencializam, é nesse caso que a paixão pode se tornar aliada do amor. (KEHL, M.R., 1987, p.484).

É essa descoberta que direciona o eu-lírico à reflexão acerca de outras formas de paixões, entre as quais as que envolvem os padecimentos sociais do povo de Cabo Verde:

Quero sim

que um ódio desmesurado se acumule

e meu coração bata descompassado

a cada genocídio acontecido

pela guerra, pela fome, pela sida

Quero sim

que a solidariedade me chame

imperativa

quando as crianças

mancas

aleijadas

famintas

esfarrapadas

despojos de guerras sem glória

barrarem todos os caminhos.

(DUARTE, V., 2001 , pp. 62-63) 
A par das desilusões e desencantos, o sujeito-poético, em intertextualidade com conhecidos versos do poeta cabo-verdiano Ovídio Martins que se rebelou contra a evasão, também diz não mais querer emigrar, rompendo com a idéia da insularidade que durante muito tempo aprisionou os cabo-verdianos:

Desvendando o segredo do amor quero permanecer na ilha

(...)

Não quero mais partir!

De malas desfeitas quebrarei na ilha a prisão das ilhas e voarei para lá do horizonte com os pés fincados na areia (...) (DUARTE, V., 2001 , pp. 64-65)

A conquista desse amor livre dá condições ao sujeito lírico de refletir política e poeticamente não só sobre seu papel feminino, mas sobre as condições sub-humanas de vida da gente pobre do Arquipélago.

Em Preces \& súplicas ou Os canticos da desesperança, Vera Duarte dedica os poemas ao ser humano, alertando, principalmente, para a crescente e assustadora perda da humanidade nesta época neoliberal, onde a globalização da pobreza e da intolerância se estende a todos os países e continentes, mesmo àqueles que costumam ser chamados de "desenvolvidos".

Atualmente, o conceito de pobreza, segundo Oscar Lewis, um dos reconhecidos estudiosos do assunto, no livro Antropología de la pobrez̧a.(1961), não se define, apenas, por questões econômicas de desigualdades sociais, mas também pode ser entendido como penúria espiritual, ética, cultural, moral; neste último caso, temos a "corrosão do caráter" que, de acordo com o historiador Richard Sennett (SENNET, R., 1999), vem-se apresentando como uma das tendências definidoras das sociedades contemporâneas regidas por exacerbados valores neoliberais.

A poesia de Vera Duarte não tece loas ao sucesso, ao consumo, ícones do mercado, onde as próprias pessoas se transformam em mercadorias e, na maioria das vezes, simulacros de produtos originais. Sua poiesis dá as costas a esse 
tipo de progresso, buscando exorcizar a barbárie através de intenso exercício de captação de lembranças recônditas do outrora. O sujeito poético de Preces \& súplicas on Os cânticos da desesperança inicia seu itinerário poético sob o peso de um mundo esmagador que lhe deixa esgotados e pendentes os braços, curvada e abatida a cabeça. É, entretanto, pela rememoração de fogos e ritmos do San Jon, que os ventos da memória e da imaginação o transportam aos tambores da Ilha de Santiago, fazendo-o relembrar tradições que se erigem, no poema, como estratégias de fuga e reação ao apocalipse de uma modernidade esfaceladora de identidades e (his)estórias.

Meus braços esgotados pedentes de

Ombros pendentes

Minha cabeça

(pobre cabeça)

curvada abatida em abatimento tamanho...

Mas o vento redemoinhou por sobre a secretária

Fez um passo de mágica

Rufaram os tambores

E o São João soou vibrante na noite

Longínqua

Da minha terra natal

(DUARTE, V., 2005, p.11)

Subvertendo a mítica história de Salomé, segundo a qual a cabeça de São João cai numa bandeja, o sujeito poético ressurge da decadência que o cerca e, mesmo em meio às profecias de destruição do mundo e da humanidade, recebe um sopro recuperador de lembranças e raízes identitárias, conseguindo, desse modo, ouvir o soar vibrante das noites iluminadas do San Jon de sua infância.

Em grande parte dos poemas de Preces ês súplicas ou Os cânticos da desesperança, o eu poético repensa as desigualdades e a intolerância existentes no mundo:

Quarenta milhões de pessoas

Gente como tu e eu

a morrerem de fome 
neste continente de condenados

(DUARTE, V., 2005, p.29)

Alegoricamente, o sujeito lírico faz reviver os cavaleiros do Apocalipse bíblico, assim como os sete selos e os antigos pecados capitais, só que retualizados, poeticamente, na modernidade africana: fome, guerra, corrupção (dos maus governos), sida, estupidež, tirania e indiferença.

Uma profunda impotência percorre a maioria dos poemas, embora, em muitos deles, é pela arte da palavra poética - entendida como forma de luta e resistência - que a esperança de mudanças se delineia, mesmo que com clara consciência de que as utopias hoje se expressam tênues, sob a égide do efêmero e do precário caracterizadores dos tempos atuais.

A intertextualidade com autores, artistas, líderes comunitários e políticos é uma outra faceta do lirismo de Os cânticos da desesperança. Em meio ao desencanto da época presente, o cântico de Vera Duarte faz lembrar o Cântico dos cânticos de Salomão que, na Antigüidade judaica, se erigiu como paradigma de genuíno e profundo hino de amor à humanidade. Em diálogo com poetas de Cabo Verde, busca o "longe longe" das tradições, mas critica o "terralongismo" que fez muitos cabo-verdianos emigrarem. Em consonância com o poeta Corsino Fortes, por exemplo, o sujeito poético de Preces \& súplicas on Os cânticos da desesperança procura os ritmos identitários insulares na própria musicalidade poética:

E lon longe

Do marulho à viola fria

Reconheço o bemol

Da mão doméstica

Que solfeja (FORTES, C., 1980, p.8)

Mas o cântico de Vera Duarte não se restringe apenas aos marulhos e longes de seu país; ultrapassa mares e fronteiras, indo ao encontro de outras vozes que, polifonicamente, traz para seus poemas. Adama Dieng, senegalês; Assilah, cidade no Marrocos, onde aconteceu em 2003 o "25 Encontro Cultural para Discutir o Mundo após o 11 de Setembro"; Eugénio de Andrade e seu poema "Improviso", no qual a imagem de "uma rosa depois da neve" 
metaforiza a angústia da existência humana a se debater entre o efêmero e o desejo de perenidade; Sérgio Vieira de Melo e suas campanhas para diminuir os "excluídos da terra" _ todos fazem parte do chamamento do eu poético que tenta acender alguma esperança na humanidade por intermédio de suas preces e súplicas que visam a devolver aos homens parte dos ideais perdidos e a crença em si próprios.

Em meio à desesperança, a voz lírica enunciadora, contudo, abre perspectivas para recobrar os caminhos dos sonhos:

O som da minha voz soou longe

nas longes clareiras

Dos matos cerrados da minha África mãe

Dos matos cerrados de homens em armas

Em feitos gloriosos

À procura do sonho

(...)

Para quando o sonho acordado?

(DUARTE, V., 2005, p.14)

O sujeito poético apela, assim, para uma poesia da sensibilidade, da luta pela igualdade e pelos direitos humanos. Recupera Eugénio de Andrade como poeta de grande trabalho com a densidade da linguagem; faz dialogarem as metáforas da rosa de Eugénio e a da rosa mirabílica da geração poética do pós 25 de abril em Cabo Verde.

Ao convocar Adama Dieng, senegalês que foi eleito para o Tribunal de Rwanda, ou Madre Teresa de Calcutá, mãe dos pobres e oprimidos do mundo, o sujeito lírico critica os desertos atuais de utopias, sonhos, esperanças, o aumento de corrupção em quase todos os países, mas abre também espaços para um "holocausto redentor":

\footnotetext{
É preciso uma fé

que mova montanhas

e um holocausto redentor

que devolva os homens aos ideais

Não quero morrer agora
} 
Pois quero aceitar

de nós

a imagem devolvida dos espelhos

(DUARTE, V., 2005, p.23)

Esta fé a que alude a voz poética enunciadora é da mesma estirpe daquela preconizada pelo estudioso da poesia Claude Esteban, quando defende que é necessário procurar significações utópicas ainda hoje:

Dar sentido é reunir o que está separado (...). É juntar tudo o que perdeu o próprio sentimento e a esperança da relação: é, em sua acepção primeira, praticar um ato religioso. E, não o escondo, é a um ato de fé que convido o poeta de nosso tempo, mas a um ato de fé no mundo que o cerca. (ESTEBAN, C., 1991. p. 214)

Seguindo tal dicção, o Cântico de Vera Duarte, apesar de ser um canto da desesperança, não perdeu a fé nos homens e no mundo. É um ato de fé, pois carrega ainda a sacralidade dos sonhos acordados, a religiosidade de tentar "religar" ideais e sentimentos perdidos na contracorrente dos novos tempos de consumo desenfreado.

Para alcançar a redenção almejada, o sujeito poético organiza os poemas do livro em sete partes como se fossem "sete preces para a recuperação do Humano". A primeira homenageia Eugénio de Andrade; a segunda, Adama Dieng; a terceira, o Congresso Cultural de Assilah em defesa dos direitos humanos; a quarta é a prece em intenção às vozes sem eco, aos milhares de anônimos e excluídos da Terra; a quinta é uma homenagem-oração a Sérgio Vieira de Melo que morreu lutando pela liberdade humana; a sexta é um desabafo indignado do eu lírico que se emociona e se revolta com a vida das crianças africanas e sua constante tragédia de fome, dor, orfandade, uma vez que sempre envoltas nos sete pecados capitais do mundo de hoje, mundo que as abandona, pois, como meras mercadorias, são compradas, vendidas, violadas, abusadas, exploradas, maltratadas, seviciadas; a sétima e última prece refere-se à ilha de Gorée, no Senegal, que, no passado, foi centro ativo do tráfico de escravos, depósito de "ossos amontoados de gente que não viveu" (DUARTE, V., 2005, 
p.48), conforme declara o sujeito lírico, consternado diante de lembranças de tamanha opressão.

Após as preces, o sujeito poético percebe que é urgente gestar um novo mundo. Repensa as imagens negativas da história da mulher sempre oprimida, violada, prostituída, a vender o sexo e a labutar para o sustento dos filhos. Conclama, então, a figura feminina a se libertar da miséria e do jugo masculino, a ganhar forma e corpo para viver as lutas contemporâneas em meio às desesperanças bloqueadoras das utopias.

\author{
Tempos novos \\ ideais recuperados \\ brilho no ar e transparência em tudo \\ serão espelho \\ onde se refletirá a imagem \\ diferente e subversiva \\ da mulher de hoje \\ a ganhar forma \\ a ganhar corpo \\ a crescer e viver \\ (DUARTE, V., 2005, p.60)
}

Esse livro de Vera Duarte se encerra com um "Cântico Final e Redentor", onde o eu poético recupera um nós coletivo, expressando, na primeira pessoa do plural, seus desejos de futuro e a recusa do presente opressor:

esconjuraremos juntos

as desgraças do Tempo que passa

gloriosamente recusando

a sorte, a morte e os sacrilégios.

(DUARTE, V., 2005, p.66)

No cântico final, a par da dispersão e do desencanto contemporâneos, se mantém a crença na insurreição dos homens e das palavras, pois "para lá da ilha, /só existe a poesia" (DUARTE, V., 2005, p.62). Ao fim da leitura, fica a certeza de que o Cântico de Vera Duarte busca desesperadamente recuperar a 
"palavra perdida", aquela capaz de erguer "as pálpebras da noite", deixando vislumbrar, além da ilha, a luz intensa que brota da poesia.

Além de Vera Duarte, destacam-se no panorama da poesia cabo-verdiana pós-1980: Manuel Delgado, Canabrava, David Hopffer Almada, Kaliosto Fidalgo, Orlando Rodrigues, Euricles Rodrigues, Alzira Cabral, Alberto Lopes, Ana Júlia Sança, Binga, José Cabral, Luís Tolentino, José Luís Tavares, Paula Martins, Vasco Martins, José Luís Hopffer Almada, entre muitos outros. Essa geração de poetas reúne tendências bastante variadas. De acordo com Simone Caputo Gomes, reconhecida especialista na literatura de Cabo Verde,

as questões consideradas como tradicionalmente ligadas à crioulidade ou caboverdianidade _ a seca, a chuva, a fome, o trabalho, a pesca da baleia, o mar, a insularidade, a emigração _ são retomadas em outro contexto, em conjunto com novas questões como as lutas e as desigualdades sociais vistas num contexto pós-colonial, o desencanto, o desespero, a solidão, a morte, a existência pessoal, o humor, a ironia , a indagação de Deus, visando conjugar aspectos nacionais e universais. ( GOMES, S. C. , In: SECCO, C., 1996, pp. 65-66)

$\mathrm{Na}$ nova poesia cabo-verdiana o mar apresenta-se, agora, como território de reflexão, de mergulho nas profundezas interiores e existenciais, como local de passagem e de abertura para o mundo. Como declara Manuel Delgado, (...) venho do mar / e o meu amplexo / rodeia a cintura do mundo. (DELGADO, M., In: ALMADA, J.L.H., 1991, p. 347).

Os poetas dessa geração têm a consciência do atual vazio cultural e social existente no Arquipélago. José Luís Hopffer Almada alerta para o perigo dos sonhos fenecendo, apodrecidos. Outros poetas efetuam esse tipo de denúncia, utilizando-se do humor e da ironia para evidenciarem o abalo dos antigos ideais libertários.

Apesar do clima de descrenças, há também os que defendem o resistir pela ação da palavra poética, metaforizada pela rosa mirabílica a desafiar o sol e o deserto. Canabrava, por exemplo, com imensa lucidez política, propõe uma "nova largada":

$\mathrm{Na}$ hora $\mathrm{H}$ da largada a saudade é eco que ressoa 
regando o pranto de quem fica

E quando tuas veias

Forem sangue-do-sangue-do-povo-das-ilhas

Banhando de suor \& sacrifício

Os oceanos do mapa-mundi

E o regresso

É suor \& sacrifício

Sangue + cicatriz

Alento nas veias do progresso!

(CANABRAVA, In: ALMADA, J.L.H., 1991, pp. 97-98).

Esse poema, em intertextualidade com o poema "Nova Largada" ( FORTES, C., 1980, p. 26), de Corsino Fortes, ressemantiza a imagem do partir e o tema da diáspora africana. O diálogo intertextual é, nesse texto, tríplice, pois, além de retomar versos do célebre poeta cabo-verdiano Corsino Fortes, faz a interlocução, também, com o poema "Adeus à Hora da Largada" ( NETO, A.,1985, p.9), do angolano Agostinho Neto. Nesse texto, há a denúncia da dilaceração decorrente do tráfico negreiro. No de Corsino, o sujeito poético reagencia o tema da viagem, concebendo-a como partida e regresso; o eu lírico vai carregado do sangue da terra e dos marulhos do mar, pretendendo voltar, já que seu polegar ficou plantado nas ilhas. No poema de Canabrava, o partir já é regresso. O sujeito poético está aberto aos oceanos do mapa-mundi; sabe da estreiteza cultural das ilhas e tem consciência de que o progresso precisa ser buscado fora, mas com "suor \& sacrifício". Propõe, assim, um partir que já é regressar, ambos prenhes de "pão \& suor", porque têm clareza de que a liberdade não pode ser conquistada só com fonemas, mas também com trabalho árduo e luta diária. A produção de Canabrava anuncia uma poiesis não mais apenas preocupada com a realidade cabo-verdiana. Quer uma poesia que singre os mares de todos os oceanos (CANABRAVA, In: ALMADA, J.L.H., 1991, p. 95), pois compreende a urgência e a necessidade de diálogos literários que conjuguem o local e o universal. Desse modo, viabiliza o desejo de que a poesia de Cabo Verde não se insularize e não fique fechada em si mesma. Intui que, em tempos neoliberais, a poesia precisa se irmanar com a de povos irmãos para não sucumbir às muitas pressões contemporâneas. 


\section{Referências bibliográficas:}

ABDALA JR., Benjamin. De vôos e ilhas. São Paulo: Ateliê Editorial, 2003.

AGOSTINHO NETO, A. Sagrada esperança. São Paulo: Ática, 1985.

ALMADA, José Luís Hopffer [Organizador]. Mirabilis: de veias abertas ao sol. Lisboa: Caminho, 1991.

BARTHES, Roland. O rumor da língua. Lisboa: Edições 70, 1984.

BOSI, Alfredo. In: NOVAES, A. Tempo e história. São Paulo: Companhia das Letras, 1992.

CANIATO, Benilde Justo.Percursos pela África e por Macau. São Paulo: Ateliê Editorial, 2005.

DUARTE, Vera. A manhã amadrugada. Lisboa: Vega, 1993.

DUARTE, Vera. O arquipélago da paixão. Mindelo: Edições Artiletra, 2001.

DUARTE, Vera. Preces \& súplicas ou Os cânticos da desesperança. Praia: Instituto Piaget, 2005.

ESTEBAN, Claude. Crítica da razão poética. São Paulo: Martins Fontes, 1991.

FORTES, Corsino. Pão \&o fonema. 2. ed. Lisboa: Sá da Costa, 1980.

GOMES, Simone Caputo. "A poesia Africana de Língua Portuguesa em Voz de Mulher”. Cadernos da UFF, no. 8. Niterói, 1993.

GOMES, Simone Caputo . "Percurso da poesia cabo-verdiana até a atualidade". In: SECCO, Carmen Lucia Tindó (Org.). Atas do I Seminário das Literaturas Africanas de Lingua Portuguesa da Faculdade de Letras da UFRJ. Rio: Setor de Publicações da Faculdade de Letras da UFRJ, 1996.

HAMILTON, Russell. Literatura africana, literatura necessária. Angola. Lisboa: Edições 70, 1981. v. I.

LEWIS, Oscar. Antropología de la pobreza. México: Fondo de Cultura Económica, 1961.

SANTILLI, Maria Aparecida. Africanidade. SP: Ática, 1985.

SENNETT, Richard. A corrosão do caráter. Rio de Janeiro: Record, 1999. 